\title{
Otimização de sistema de multi-barreira para tratamento de esgoto biotratado
}

\section{Eric B. Barbosa*, Renato F. Dantas.}

\section{Resumo}

A utilização de Processos oxidativos avançados (POAs), para tratamento de efluentes tem sido muito estudada ao longo dos últimos anos e empregada para remover diversos compostos e realizar tratamento de águas residuárias. É uma técnica eficiente, porém com algumas limitações. Estudos atuais tendem a combinar as características mais importantes de cada tecnologia visando reduzir os custos, agregando a eficiência de cada tecnologia, e testando variadas combinações para se obter a melhor combição de custo e eficiência. Os experimentos foram realizados com amostras da estação de tratamento de efluentes secundários da Escola de Tecnologia da Universidade Estadual de Campinas - UNICAMP de Limeira-SP. O objetivo desse trabalho foi analisar a eficiência de quatro configurações diferentes de tratamento multibarreiras alterando os POA de cada um deles. Os resultados demonstraram que as configurações $\mathrm{O} 3+\mathrm{GAC}+\mathrm{O} 3$ e UV/H2O2 + GAC + O3 foram as mais eficientes.

\section{Palavras-chave:}

Carvão ativado, processos oxidativos avançados, ozonização

\section{Introdução}

Os processos convencionais de tratamento de água e esgoto para a remoção de contaminantes mais amplamente utilizados são os físico-químicos e biológico, por serem mais barato. Porém, tais tratamentos não removem todos os poluentes orgânicos contidos nas águas, além de muitas vezes não atenderem a qualidade exigida pela legislação. [1,2]

Este projeto simula em escala laboratorial um tratamento de efluente biotratado, com objetivo de determinar os melhores sistemas de tratamento em função da remoção das principais características físico-químicas do efluente.

\section{Resultados e Discussão}

O trabalho foi divido em quatro sistemas de tratamento para que se pudesse determinar o melhor tratamento, como mostra a Tabela 1.

Tabela 1. Sistemas de Tratamentos.

Tratamentos

$\begin{array}{cc}1 & \mathrm{O}_{3}+\mathrm{GAC}+\mathrm{O}_{3} \\ 2 & \mathrm{O} 3+\mathrm{GAC}+\mathrm{UV} / \mathrm{H}_{2} \mathrm{O}_{2} \\ 3 & \mathrm{UV} / \mathrm{H}_{2} \mathrm{O}_{2}+\mathrm{GAC}+\mathrm{UV} / \mathrm{H}_{2} \mathrm{O}_{2} \\ 4 & \mathrm{UV} / \mathrm{H}_{2} \mathrm{O}_{2}+\mathrm{GAC}+\mathrm{O}_{3}\end{array}$

Para cada sistema foi analisado antes e após cada tratamento, as principais características físico-químicas da amostra, conforme a Tabela 2.

\begin{tabular}{cccccc}
\multicolumn{6}{l}{ Tabela 2. Parâmetros fisíco químicos do tratamento } \\
\hline \multirow{2}{*}{ Parâmetros } & $\begin{array}{c}\text { Antes do } \\
\text { tratamento }\end{array}$ & $\begin{array}{c}\text { Tratamento } \\
1\end{array}$ & $\begin{array}{c}\text { Tratamento } \\
2\end{array}$ & $\begin{array}{c}\text { Tratamento } \\
3\end{array}$ & $\begin{array}{c}\text { Tratamento } \\
4\end{array}$ \\
\hline pH & 6.94 & 7.15 & 7.09 & 6.86 & 7.12 \\
SST & 74.85 & 13.4 & 20.6 & 11.3 & 10.2 \\
Alcalinidade & 487.6 & 89.8 & 102.2 & 94.7 & 87.6 \\
Turbidez & 74.4 & 8.1 & 9.3 & 8.7 & 7.3 \\
UV254 & 1.28 & 0.23 & 0.26 & 0.31 & 0.25 \\
Cor & 346 & 2 & 6 & 3 & 2 \\
DQO & 202 & 22.4 & 28.6 & 32.3 & 24.5 \\
DBO & 38.6 & 14.0 & 30.1 & 25.7 & 12.3 \\
\hline
\end{tabular}

A partir destes resultados pode-se determinar a remoção das características físico-químicas para cada tratamento conforme o Gráfico 1.

Gráfico 1. Remoção dos parâmetros físico-químicos

\section{Remoção dos Parâmetros analisados}

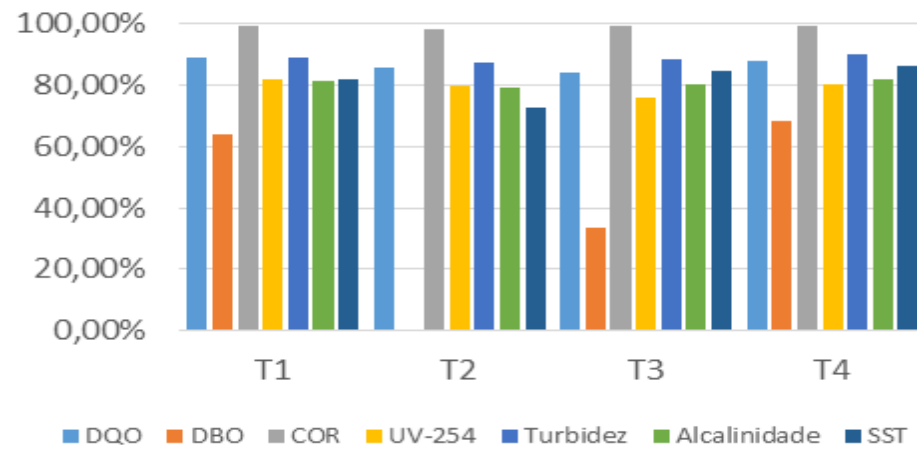

\section{Conclusões}

Com base nos resultados obtidos com os experimentos, conclui-se que que todos os tratamentos foram eficientes na remoção dos parâmetros analisados, bem como na remoção da matéria orgânica onde o tratamento 1 obteve maior remoção de matéria orgânica, no entanto, o tratamento 4 , apesar de não ter a maior remoção de matéria orgânica, foi estatisticamente em mais eficiente na remoção de outras características analisadas.

\section{Agradecimentos}

Ao $\mathrm{CNPq}$ pelo apoio financeiro. Ao meu orientador Renato Falcão Dantas acompanhamento do projeto, bem como a ajuda e o acompanhamento das Doutorandas Jacqueline Malvestiti e Mariana Granzoto.

1-Verlicchi, P.; Aukidy, M. A.; Zambello, E. Occurrence of pharmaceutical compounds in urban wastewater: removal, mass load and environmental risk after a secondary treatmentâa review. Science of the total environment, Elsevier. 429 (2012) 123-155.

2-Dutta, K.; Lee, M.-Y.; Lai, W. W.-P.; Lee, C. H.; Lin, A. Y.-C.; Lin, C.-F.; Lin, J.-G. Removal of pharmaceuticals and organic matter from municipal wastewater using two-stage anaerobic pharmaceuticals and organic matter from municipal wastewater using two-stage
fluidized membrane bioreactor. Bioresource technology, Elsevier. 165 (2014) 42-49. 